M. Klimczuk-Kochańska, A. Klimczuk, New Economy, Food, and Agriculture, [in:] P.B. Thompson, D.M. Kaplan (eds.), Encyclopedia of Food and Agricultural Ethics, Second Edition, Springer,

Dordrecht 2019, pp. 1893-1898, https://doi.org/10.1007/978-94-007-6167-4 629-1.

\title{
New Economy, Food, and Agriculture
}

Andrzej Klimczuk

Collegium of Socio-Economics, Warsaw School of Economics, Warsaw, Poland

Magdalena Klimczuk-Kochańska

Faculty of Management, University of Warsaw, Warsaw, Poland

\section{Introduction}

Consumers are becoming increasingly more informed about food systems and are interested not only in healthy, safe, and tasty food but also in sustainable production, animal welfare, climate changes, and food waste. Consumers are also more focused on changing their lifestyle related to improved health knowledge and nutrition education (Timmer 2005). Maxwell and Slater (2004) have proposed criteria to evaluate food systems, including nutrition and health, rights and influence, security, sustainability, equality, and social inclusion. The authors also point out that the primary international institutions in the food value chain are not only the Food and Agriculture Organization and World Health Organization but also United Nations Industrial Development Organization, International Labour Organization, and World Trade Organization.

The emerging trends in the food system are features of the "new economy." This term describes the outcome of the transition from production- and manufacturing-based economy to a service-based or post-industrial economy at the end of the twentieth century. The traditional production factors such as cheap labor, land, and raw materials lose their importance in generating profits and competitiveness. The key is understanding of food consumer demand, knowledge of food industry and agriculture employees based on creativity, and flexibility of processes of production.

\section{The Relations of New Economic Systems and the Food and Agricultural Industries}

The new economy concept is primarily the result of socio-cultural, economic, and technological changes. This paradigm is related to the economy as a social activity. From this point of view, one of the crucial issues in the new economy is justice that reverses the trend towards greater inequality and continuing economic disparities. It means that the "security" in this kind of economy could be based on relationships, community, and collaboration rather than wealth and accumulation of capital. Companies in the new economy have to be more "consumer-centric" (Hammer 2000). Ideas for being sustainable, environmentally friendly, and ecological are crucial. Finding new ways to use and re-use or recycle the resources are common trends. 
M. Klimczuk-Kochańska, A. Klimczuk, New Economy, Food, and Agriculture, [in:] P.B. Thompson, D.M. Kaplan (eds.), Encyclopedia of Food and Agricultural Ethics, Second Edition, Springer,

Dordrecht 2019, pp. 1893-1898, https://doi.org/10.1007/978-94-007-6167-4 629-1.

Another essential element of the new economy is technological change. It relates to the introduction and development of emerging technologies and the increase of science-intensive economy. It is mainly seen in high technology sectors such as robotics, electronics, telecommunications, chemistry, biotechnologies, pharmaceutics, and air and space technologies. Information and communications technologies (ICTs) play a unique role in the development of the new economy as they contribute to the transformation of social and economic structures due to the development of human relationships through various devices that primarily use the Internet. It is worth paying attention to the fact that in many cases, these new relations are also of an economic nature, but they lack appropriate legal regulations that cannot keep pace with changes in the economy. This phenomenon is explained by concepts such as the "cultural lag" (W.F. Ogburn) and "future shock" (A. Toffler).

This entry will present selected ideas of new economic systems that underline specific sectors that are also associated with changes in the food and agriculture industries. These are: (1) the sharing economy, (2) the circular economy, (3) the blue economy, (4) the creative economy, and (5) the digital economy. Many authors use these concepts interchangeably or as interconnected. For example, the sharing economy is sometimes described also under the notions such as the access economy, the labor-light economy, the freelance economy, the gig economy, the platform economy, the on-demand economy, the collaborative economy, the peer-to-peer economy, the reputation economy, or the trust economy. The circular and blue economies may be interpreted as further developments of ideas such as the green economy, the purple economy, the hydrogen economy, the biobased economy, and the decarbonized economy. The analyses of the creative economy are extended by notions of the attention economy, the experience economy, the post-scarcity economy, the conceptual economy, and the cognitive-cultural economy. Finally, the digital economy is sometimes described with related concepts such as the information economy, the knowledge economy, the learning economy, the industrial information economy, the new manufacturing economy, the network economy, and the virtual economy.

\section{Sharing Economy}

The food systems in many countries have become so industrialized that most of the food production processes are done by unknown people using unknown technologies in unknown places. Nevertheless, consumers buy and consume food, which means that they trust in food and its producers and processors. In recent years, the sharing economy has been on the rise, and 
M. Klimczuk-Kochańska, A. Klimczuk, New Economy, Food, and Agriculture, [in:] P.B. Thompson, D.M. Kaplan (eds.), Encyclopedia of Food and Agricultural Ethics, Second Edition, Springer,

Dordrecht 2019, pp. 1893-1898, https://doi.org/10.1007/978-94-007-6167-4 629-1.

it is predicted to generate a significant impact on the economy and society in general (Hamari et al. 2016). This concept refers to sharing of the use of assets that have the untapped or unused capacity. Individuals participate in sharing activities by renting, lending, trading, bartering, or swapping goods and services (Heo 2016). The sharing economy includes networking opportunities for businesses that might not exist in a different system.

Meal sharing (such as communal dinner experience) is an example of the kinds of solutions, social interactions, and motivations for participating in new activities (Bocker and Meelen 2017). In countries all over the world, bake sales and in-home restaurants are becoming more common. Unfortunately, there is a considerable problem with the regulation of this kind of trade, because in many countries selling homemade food is illegal, and there are problems with no standards of hygiene.

Another category of motivation for the sharing economy is the environment. For many people, their involvement in the sharing economy is essential to reduce their use of scarce natural resources and increase efficiency in the use of goods (e.g., the zero-waste movement). The idea of sustainability and "to be green" are valid drivers among sharing economy users (Bocker and Meelen 2017; Hamari et al. 2016). In many countries, the initiatives for sharing include food banks, leftover food from individuals, or surplus food from supermarkets. Such activities are aimed at limiting the amount of food waste. Moreover, the sharing economy is characterized by relations between the providers and the users with economic incentives for cooperation. For example, kitchen owner can earn extra income from renting their space when it was previously not being used, while housing and supporting another business.

In this new economic system, entrepreneurs value the reclamation of the commons through the open sharing of knowledge, resources, and tools. The examples include the open-source software movement and open-source hardware projects utilized in, for example, shared labs for food processors, fab labs, and living labs related to agriculture projects, or urban farming spaces. Food companies are increasingly interested in ideas such as open innovation or triple and quadruple helix model of innovation, where the source of changes in products and services are based on ideas originating from outside the enterprise.

It is important to underline that the notion of sharing economy that emerged at the early twenty-first century is sometimes confused with the features of earlier concepts such as the informal economy, the gift economy, the barter economy, the subsistence economy, and the idea of the social and solidarity economy (also known as the popular economy, the economy of the poor, the economy of local communities, the civic economy, the labor economy, and the 
M. Klimczuk-Kochańska, A. Klimczuk, New Economy, Food, and Agriculture, [in:] P.B. Thompson, D.M. Kaplan (eds.), Encyclopedia of Food and Agricultural Ethics, Second Edition, Springer,

Dordrecht 2019, pp. 1893-1898, https://doi.org/10.1007/978-94-007-6167-4 629-1.

cooperative economy). The concept of the social and solidarity economy emerged in Europe in the first half of the nineteenth century and still plays a significant role in the poverty reduction. The premise of this system is the activation of disadvantaged groups, including farmers and people living in rural or peripheral areas, through autonomous, collaborative, and democratic governance of entities such as social enterprises, cooperative banks, mutual insurance companies, fair trade organizations, including the food production certification systems, associations that are establishing local currencies, participatory budgeting models, self-help, and mutual aid groups.

\section{Circular Economy}

The notion of circular economy underlines collaborative models as essential to maximizing utilization of already used products and resources (Geissdoerfer et al. 2017). The necessity of using products in the circular flow is modeled after natural resources, for example, timber, food, and technical resources such as metals and minerals. These resources have to be transformed and used in the long term to implement the idea of "nothing is lost."

Achieving the circular economy is especially related to reduction and sustainable use of natural resources, use of resources with less environmental pressure, and prevention of resource waste in processes of production and residue streams. The implementation of this model covers changes in technologies used in production, new methods of resource processing, and changing consumers' habits and governance policy.

One challenge to a circular economy in the food system is closed loops of resources. For example, the traditional agriculture uses the well-known mechanism of returning nutrients to farms by turning agricultural waste into fertilizer. The benefits of it are regeneration of soil and reduction of reliance on artificial fertilizers. Another critical issue is recovering resources from by-products. It can be implemented, for example, recovering energy from alternative renewable feedstocks, which are the result of food production.

The optimization of crucial elements of food and agriculture production and manufacturing helps to save some soil, water, energy, and nutrients but cannot be done without looking at feed, cultivation, and breeding safety standards. Sometimes the, residue stream is contaminated, and it is not possible to use it in the food production. Or it requires too many other resources for treatment for secondary usage. Sometimes various kinds of waste cannot be used in the production, for example, animal bones in food for people. Thus, food wastage has to be used effectively in food processing as well as under the law. 
M. Klimczuk-Kochańska, A. Klimczuk, New Economy, Food, and Agriculture, [in:] P.B. Thompson, D.M. Kaplan (eds.), Encyclopedia of Food and Agricultural Ethics, Second Edition, Springer,

Dordrecht 2019, pp. 1893-1898, https://doi.org/10.1007/978-94-007-6167-4 629-1.

Another concept in the circular economy is the short supply chains, also known as "farm to fork." The carbon footprint is lower, and it is positive for the local labor market. There are beneficial digital technologies that allow to measure, track, and locate food and other organic materials with more precision enabling better management and allocation of resources. It is also vital to understand and change consumers' habits. Consumers increasingly are interested in buying organic food. They want to know the source of food, the methods of their production, and are interested in reducing waste. Food labeling - and better consumer understanding of labeling - is important to achieve these values.

The idea of the circular economy has a considerable influence on developing innovative food products and services in the food industry and agriculture. For example, urban farming gives the ability to produce food in underutilized urban roof spaces. This idea also has environmental benefits by reducing building energy demands and allows the use of rainwater. Even transnational corporations started to notice and support such trends. Another kind of innovation in this field is the production of fruits and vegetables in the shape right for crisps, chips, and other products, both for the sake of consumers and to decrease costs of transportation. This innovation reduces losses in the processes of peeling and cutting the products. One of the reasons for production of "lab-grown meat" is to find new sources of proteins coming from more efficient processes. It is especially important because the food produced in the food systems is also used to feed animals for meat production.

\section{Blue Economy}

The circular economy is closely related to the implementation of the idea of the blue economy. This notion refers to some options for economic development, in which the economy responds to the needs of people. The blue economy stimulates entrepreneurship and new job opportunities (Pauli 2010). The primary focus of the blue economy is eliminating waste and pollution. It has to be based on scientific analyzes that identify the best solutions in business. Also, the social capital, that is cooperation and trust between economic entities, plays a significant role in the production of healthier and cheaper products (also known as the development of the "white economy").

Elements that make-up the concept of the blue economy are: innovation, market, cash flow, and potentials. Innovation is the engine of growth in the blue economy. It is essential to identify the problems and find innovative solutions and opportunities. Significant is a market because sometimes consumers are conservative and slow adopt novel solutions and products. Cash 
M. Klimczuk-Kochańska, A. Klimczuk, New Economy, Food, and Agriculture, [in:] P.B. Thompson, D.M. Kaplan (eds.), Encyclopedia of Food and Agricultural Ethics, Second Edition, Springer,

Dordrecht 2019, pp. 1893-1898, https://doi.org/10.1007/978-94-007-6167-4 629-1.

flows can be generated without any public subsidies, but for example, by transforming the waste into new raw materials. The innovations can generate new potentials for new sources of cash flow, new jobs, and build social capital.

The concept of the blue economy is also known as the "ecolonomy," or an approach to business based on strict environmental and ethical principles that is also sustainable and commercially profitable (Druon 2015). The concept of the blue economy can be seen as an alternative to the green economy. Green products are still categorized as luxury products, while green economy projects rely on special funds, subsidies, and tax cuts leading to thinking that implementation of this concept is expensive and not affordable for all countries. The blue economy provides ways, strategies, and alternatives which could overcome the current environmental problems. This idea is attractive for the food and agriculture industry.

Some shared concepts of the blue economy and circular economy are upcycling, recycling, remanufacturing, industrial ecology, and renewable energy. The fundamental idea of the blue economy is the cascading nutrients and energy in the ecosystems. An example of this is the idea of the production of mushrooms grown on coffee grounds as a by-product.

The idea of a blue economy is sometimes modeled on the concept of biomimicry (Benyus 1997). The main idea of it is to inspire from the genius of nature to innovate biotechnologies or processes that imitate nature. The biomimicry means the adoption of solutions that are extracted from the evolution of nature. Products from such systems are less energy-intensive, provide less adverse external effects to the environment, and are also probably healthier. In the context of the food production and manufacturing, this idea is represented by terms such as natural, bio, bioagriculture, and eco-economy.

An example of technological biomimicry is juice bottle design created in essence of the pistil structure of a flower. An agricultural biomimicry example is growing food with using the prairies as a model system for producing stable natural ecosystems. Another example inspired by nature can be even the living filtration system as an alternative form of farm drainage. In contrast to modern farming that relies heavily on artificial fertilizers that get washed away and pollute water in rivers, this solution can trap nutrients in the soil. The blue economy assumes that it requires creativity from the society, including the employees of organizations.

\section{Creative Economy}

One of the main features of the new economy is creativity: thinking about new things or making an original combination of existing elements. The effect of creativity consists in breaking up a 
M. Klimczuk-Kochańska, A. Klimczuk, New Economy, Food, and Agriculture, [in:] P.B. Thompson, D.M. Kaplan (eds.), Encyclopedia of Food and Agricultural Ethics, Second Edition, Springer,

Dordrecht 2019, pp. 1893-1898, https://doi.org/10.1007/978-94-007-6167-4 629-1.

learned pattern of thinking and using its knowledge to generate new ideas. Most theorists have defined creativity as the development of ideas about products, practices, services, or procedures that are novel and potentially useful to an organization. Creativity depends on the context in which new products, ideas, and behaviors are offered (Klimczuk-Kochańska 2017).

There is a relationship between creativity, design, and innovation. For example, Baer (2012) treats innovation as an umbrella concept that includes creativity and its implementation. Florida (2002) shows that nowadays, there is a transition from blue and white collars workers to no collar workers; it is a trend of development of a creative class represented by knowledge workers, intellectuals, designers, and artists. The developments in the creative industries such as design, mass media, and marketing are also related to ideas such as the silver economy or the longevity economy that drawn attention to new products and services for ageing and older consumers, including food, pharmaceuticals, dietary supplements, and innovative kitchen equipment for people with disabilities (Klimczuk 2015).

The idea of the creative economy is also found in the food sector. It is difficult to analyze the topic of creativity and innovation in the field of traditional industries with low technological potential, which is generally considered in the literature as characterized by low creativity and limited innovativeness. Changes in world market trends show that the development of the lowtech sector is in a state of confusion, that is, without a focus on innovation and encouraging employees to take creative action. Focusing on radical innovations may not be particularly important for the food business because of the conservative consumer behavior described as consumer inertia. Especially design-oriented concepts require not only the technical knowledge but also the creativity of the organization's employees. Without the creativity, many food products and related services with different taste, color, or packaging would never have been created.

\section{Digital Economy}

Another significant aspect of the new economy is the digital economy. Digital economy refers to an economy that is based on digital computing technologies. Solow (1970) was implying the impacts of technological and scientific development in the present understanding of the effects of ICTs. This technical change leads to, for example, faster growth in manufacturing productivity. The digital changes are found in e-business infrastructure (hardware, software, networks, and human capital), e-business (business conducted over computer-mediated networks), and e-commerce (transfer of goods online) (Mesenbourg 2001). Nowadays, it seems 
M. Klimczuk-Kochańska, A. Klimczuk, New Economy, Food, and Agriculture, [in:] P.B. Thompson, D.M. Kaplan (eds.), Encyclopedia of Food and Agricultural Ethics, Second Edition, Springer,

Dordrecht 2019, pp. 1893-1898, https://doi.org/10.1007/978-94-007-6167-4 629-1.

that the change in the ICTs, lower prices for IT devices such as smartphones and tablet computers, and growing availability of Internet and Wi-Fi networks are vital aspects supporting the substantial growth of the sharing economy. For example, thanks to these opportunities to interact with other people, especially the Millennials who are already well-connected and networked and value the realness, honesty, and authenticity of things in life (Van den Bergh and Behrer 2016). This generation is considered the leading adopters of the solutions from the field of the sharing economy.

The digital economy can lead to sale prices close to zero or free. It may not only create many businesses, but now most of the companies are threatened by the digitization of the economy. The most popular concepts are now, for example, the Internet of Things (IoT), blockchain, big data, and e-commerce.

In the food and agriculture industry, the digital economy integrates the agile culture and processes through a whole supply and value chains. It is crucial because of many reasons but mainly for healthy and safe food. Digital technologies in food production and manufacture can be used in solving problems, such as the traceability of food and the use of satellite tracking of lorries delivering food to distribution centers. However, the transportation also includes the critical issue of collecting data from the course of transport and, for example, changes in temperature in a cold store truck. Significant are bases of "data trust" which for the food sector help to underpin data sharing, trust, and inter-operability within complex supply chains.

Although there are interesting potentials for growth, many agri-food and agricultural enterprises have not bridged the digital divide. Moreover, the IoT solutions are increasingly related to services for consumers. An excellent example is a use of smart refrigerators and cooking devices to improve health outcomes and reduce waste.

\section{Conclusion}

This entry examined various economic systems related to the broader idea of the new economy in food and agriculture, namely, the sharing economy, the circular economy, the blue economy, the creative economy, and the digital economy. These systems support and use different forms of capitals and technology changes. However, none of these systems can meet all the needs of the food industry and agriculture. These systems can, however, be mixed and combined by using features of a new economy to improve the competitiveness of food systems in light of current global trends. 
M. Klimczuk-Kochańska, A. Klimczuk, New Economy, Food, and Agriculture, [in:] P.B. Thompson, D.M. Kaplan (eds.), Encyclopedia of Food and Agricultural Ethics, Second Edition, Springer,

Dordrecht 2019, pp. 1893-1898, https://doi.org/10.1007/978-94-007-6167-4 629-1.

\section{References}

Baer, M. (2012). Putting creativity to work: The implementation of creative ideas in organizations. Academy of Management Journal, 55(5), 1102-1119.

Benyus, J. M. (1997). Biomimicry: Innovation inspired by nature. New York: Morrow.

Böcker, L., \& Meelen, T. (2017). Sharing for people, planet or profit? Analysing motivations for intended sharing economy participation. Environmental Innovation and Societal Transitions, 23,28-39.

Druon, E. (2015). Ecolonomy: Doing business and manufacturing differently. Axminster: Triarchy Press.

Florida, R. (2002). The rise of the creative class: And how it's transforming work, leisure, community and everyday life. New York: Basic Books.

Geissdoerfer, M., Savaget, P., Bocken, N. M. P., \& Hultink, E. J. (2017). The circular economy - A new sustainability paradigm? Journal of Cleaner Production, 143, 757-768.

Hamari, J., Sjöklint, M., \& Ukkonen, A. (2016). The sharing economy: Why people participate in collaborative consumption. Journal of the Association for Information Science and Technology, 67(9), 2047-2059.

Hammer, M. (2000). It's the customer, stupid. InformationWeek. (811), 264.

Heo, Y. (2016). Sharing economy and prospects in tourism research. Annals of Tourism Research, 58, 166-170.

Klimczuk, A. (2015). Economic foundations for creative ageing policy, Volume I: Context and considerations. New York/Basingstoke: Palgrave Macmillan.

Klimczuk-Kochańska, M. (2017). Importance of creativity of employees in adaptation of food companies to innovative trends in the world. Human Resources Management \& Ergonomics, 11(1), 50-64.

Maxwell, S., \& Slater, R. (2004). Food policy old and new. Development Policy Review, 21(5-6), 531-553.

Mesenbourg, T. L. (2001). Measuring electronic business. Washington, DC: US Bureau of the Census.

Pauli, G. A. (2010). The blue economy: 10 years, 100 innovations, 100 million jobs. Taos: Paradigm Publications.

Solow, R. M. (1970). Growth theory: An exposition. New York: Oxford University Press.

Timmer, C. P. (2005). Food security and economic growth: An Asian perspective. AsianPacific Economic Literature, 19(1),1-17. 
M. Klimczuk-Kochańska, A. Klimczuk, New Economy, Food, and Agriculture, [in:] P.B. Thompson, D.M. Kaplan (eds.), Encyclopedia of Food and Agricultural Ethics, Second Edition, Springer,

Dordrecht 2019, pp. 1893-1898, https://doi.org/10.1007/978-94-007-6167-4 629-1.

Van den Bergh, J., \& Behrer, M. (2016). How cool brands stay hot: Branding to generations $Y$ and $Z$. London: Kogan Page Publishers. 